\title{
Growth rate, survival and preference of porina (Wiseana spp) to selected grasses
}

\author{
S. R. Atijegbe ${ }^{1}$, S. Mansfield ${ }^{1,2}$, M. Rostás ${ }^{1}$, S. Worner ${ }^{1}$ and C. Ferguson ${ }^{2}$ \\ ${ }^{1}$ Bio-Protection Centre, Lincoln University, New Zealand \\ ${ }^{2}$ AgResearch Limited, Gerald Street, Lincoln 7608, New Zealand \\ Corresponding author: sylvesterrichard.atijegbe@lincolnuni.ac.nz
}

Porina (Wiseana spp) has become a major pasture pest in New Zealand over the past century in response to natural forest and grasslands being converted into pastures for livestock. Limited information is available on the growth and survival of porina larvae on native host species. Field collected porina larvae were fed on 5 selected native plants (Festuca actae, Aciphylla squarrosa, Poa cita, Chionochloa rubra and Phormium tenax), one exotic (Lolium multiflorum cv Manawa) and mixed species over 5 months, and the fitness response of porina to each of these grasses was measured. The most rapid growth of larvae was observed on L. multiflorum, while the slowest was on P. tenax, A. squarrosa and P. cita. The largest weight gain was on L. multiflorum. There was a significant difference in larval growth between L. multiflorum and P. tenax ( $\mathrm{P}=0.019)$. Percentage mortality was lowest on L. multiflorum (12.5\%) with the larvae surviving for 177 days. The highest mortality of $75 \%$ was recorded on P. cita which also had the lowest survival of 77 days. This study provided useful information on the development of porina on native hosts which provide a habitat for its expansion on to pasture.

\section{Oviposition strategies of large cabbage moth (Crocidolomia pavonana) on Chinese cabbage}

\author{
J.B. Sulifoa ${ }^{1}$, M.J. Furlong ${ }^{2}$ and R. Kant ${ }^{1}$
}

${ }^{1}$ School of Agriculture and Food Technology, University of the South Pacific, Apia, Samoa
${ }^{2}$ School of Biological Sciences, University of Queensland, St. Lucia, Queensland, Australia
Corresponding author: kant ra@usp.ac.fi.

Crocidolomia pavonana F. (Lepidoptera: Crambidae) is an important pest of brassica crops in Samoa and in other countries in the South Pacific. This study investigated the oviposition behaviour of C. pavonana on Chinese cabbage in Samoa. This research was carried out in field and laboratory experiments at the University of South Pacific, Samoa. The study showed that female C. pavonana oviposited more egg masses during the dark between 20:00 and 08:00 h (204.3 \pm 49.3$)$ compared to the daylight hours (9.7 \pm 1.86$)$. Female $C$. pavonana lived up to 33 days but most of the eggs were oviposited when aged 3-9 days. Linear regression analysis showed that egg mass size decreased as females aged. Younger females (ca 2-day-old) laid up to 141 eggs per egg mass, whereas older females (ca 30-days-old) laid up to 3 eggs per egg mass. Females deposited $>92 \%$ of their eggs on the lower surface of the leaf. Most eggs were found near the midrib. The eggs were also laid near the petiole (67\%), compared to the central or top (33\%) parts of the leaf. Only a few eggs were oviposited on the petiole or the stem of the plant. 